\title{
O PROCESSO DE EMPODERAMENTO DOS EGRESSOS NO PROGRAMA PÃO ESCOLA: ANÁLISE DOS REFLEXOS DO PROGRAMA
}

\author{
Frederico Divino Dias; Frederico de Carvalho Figueiredo \\ Faculdade Kennedy e Promove de Belo Horizonte; Centro Universitário UNA-BH \\ DOI: 10.15628/rbept.2019.8235
}

Artigo submetido em jan/2019 e aceito em ago/2019

\begin{abstract}
RESUMO
O presente artigo fez uma análise do Programa Pão Escola sob a perspectiva do mesmo atuar como uma ação incentivadora para iniciar os discentes no processo de empoderamento individual. O estudo ouviu um grupo de dezenove egressos para fazer as análises pertinentes. Tendo o método dedutivo e abordagem qualitativa como base metodológica, o artigo apresentou um resgate teórico para embasar a pesquisa de campo. Os dados apontaram no sentido de que o Programa não trabalha todo o seu potencial de política pública que despertaria mudanças nas vidas dos discentes. A educação profissional analisada fixa-se nas bases tradicionais de formação, distanciando-se de uma formação integral dos sujeitos. Propõe-se, ao final, a necessidade de implantar alterações com vistas a melhorar a formação do Programa.
\end{abstract}

Palavras-Chave: Educação Profissional. Empoderamento. Desenvolvimento Local. Mundo do trabalho. Educação Integral.

\section{THE PROCESS OF EMPOWERMENT IN THE PÃO ESCOLA PROGRAM: ANALYSIS OF THE REFLECTIONS OF THE PROGRAM}

\begin{abstract}
This article analyzes the 'Pão Escola' Program from the perspective of it acting as an encouraging action to initiate students in the process of individual empowerment. The study listened to a group of nineteen graduates to perform the relevant analyzes. Having the deductive method and qualitative approach as the methodological basis, the article presented a theoretical rescue to support the field research. The data indicated that the Program does not work its full potential of public policy that would bring changes in the lives of students. The analyzed professional education is fixed in the traditional bases of formation, distancing itself from an integral formation of the subjects. It is finally proposed the need to implement changes in order to improve the formation of the Program.
\end{abstract}

Keywords: Professional Education. Empowerment. Local development. World of work. Integral education.

\section{INTRODUÇÃO}

Partindo-se da grande globalização dos mercados - em meados dos anos de 1990 - devido à internacionalização da economia, foi necessário que - país adequasse e oferecesse produtos com elevados padrões 
internacionais. A partir disso, foi demandado dos trabalhadores uma maior especialização visando atender às novas carências exigidas pelo mercado. Desde então são, portanto, exigidas cada vez mais novas formas de produção, formação e acumulação do capital (ALVES, VIEIRA, 1995; BARBOSA, DELUIZ, 2008).

Agregando esta informação aos dados do IBGE (2015) é possível notar a elevação gradual da escolaridade da População Economicamente Ativa (PEA) no Brasil nos últimos anos. Os dados mais recentes - do ano de 2011 - declaram que cerca de $34,7 \%$ da PEA tinham entre 11 e 14 anos de estudo (faixa que engloba a educação básica) em contraposição a $21,7 \%$ no ano de 2001. Vê-se que atualmente a maior parte da PEA (53,6\%) ainda se enquadra na faixa de 'até 10 anos de instrução' que engloba a formação no ensino fundamental - cerca de 50 milhões de pessoas. Tratando-se da instrução de nível superior observa-se que apenas $11,7 \%$ da PEA (aproximadamente 11 milhões de pessoas) coloca-se nesta faixa.

Dada a necessidade da especialização da mão de obra, as autoridades governamentais apresentaram ao longo da história uma série de políticas que visavam suprir esta demanda: ofertar formação à população que necessita de inserção no mundo do trabalho além de ofertar ao mercado trabalhadores capacitados para tal atuação. Dentre tais políticas pode-se destacar o Programa Nacional de Qualificação (PNQ), Plano Nacional de Qualificação Profissional (PLANFOR), Programa Nacional de Acesso ao Ensino Técnico e Emprego (PRONATEC) - nível federal - (CASSIOLATO, GARCIA, 2014), o Programa Melhor Emprego - nível municipal em Belo Horizonte (PREFEITURA MUNICIPAL DE BELO HORIZONTE, 2012), dentre outros.

Alves e Vieira (1995), assim como Figueiredo e Mueller (2015), argumentam que o processo educacional de formação profissional brasileiro se limita a ser uma educação para o mundo do trabalho, por meio de um cunho técnico as estratégias formativas limitam-se à resposta imediata para o capitalismo. Exemplo disso é o sistema ' $S$ ' marcado como orientador pelo paradigma fordista de produção ${ }^{1}$.

Em seu estudo os autores Alves e Vieira (1995) argumentam que as políticas de formação profissional deveriam valorizar os trabalhadores; eles apontam a necessidade de superar o adestramento; é importante visualizar que é fundamental uma educação que trabalhe 0 ato de pensar e 0 ato de fazer. Paulo Freire também defende este mesmo ideal em sua obra 'Pedagogia do Oprimido' (1987), na qual ele faz crítica ao adestramento, à 'educação bancária' que é vista em vários momentos da história do Brasil.

Paulo Freire afirma que pela educação bancária, os sujeitos seriam meros 'recipientes', seriam meras 'vasilhas' nas quais os conhecimentos serão depositados pelos educadores, que são os detentores do

\footnotetext{
${ }^{1} \mathrm{O}$ paradigma fordista (taylorista/fordista) de produção, tinha por prerrogativa atender às demandas de uma organização social rígida e estável e, para tal, os trabalhadores executam ao longo de sua vida social e produtiva as mesmas atribuições, memorizando e repetindo operações em determinada sequência lógica (KUENZER, 2005).
} 
conhecimento. O autor reitera a ideia de que quanto mais é trabalhada a educação bancária nos sujeitos de uma sociedade, menos eles desenvolveriam um pensamento crítico sendo, consequentemente, cada vez mais dissociados do mundo ou como agentes transformadores nos locais nos quais se encontram (FREIRE, 1987). Associa-se aqui o pensamento de Gohn (2002) que afirma a necessidade do rompimento com este formato de educação para um posterior incentivo às potencialidades dos indivíduos.

Concernente aos pensamentos de Paulo Freire e de Gohn (2002) enquadram-se também os pressupostos de Baquero (2012), Perkins (2010) e Souza, Moreira e Bourguignon (2014) para os quais a partir do rompimento com a educação bancária os sujeitos teriam suas habilidades desenvolvidas e poderiam ser seres potencialmente transformadores das realidades $\mathrm{e}$ situações que os cercam.

Visando elevar a escolaridade e qualificação da população belohorizontina, a Prefeitura de Belo Horizonte apresenta o Programa Pão Escola (PPE) como uma alternativa de formar jovens para facilitar sua inserção no mundo do trabalho e consequentemente melhorar a qualidade de vida e impulsionar o desenvolvimento econômico e social da capital. Programa surgido no ano de 2001, ele oferece formação na área da alimentação no Mercado Popular da Lagoinha, onde encontra estrutura adequada para formação com uma padaria-escola e quatro cozinhas pedagógicas equipadas de acordo com as novas exigências do mundo do trabalho e legislações pertinentes.

O PPE conta com dois educadores que acompanham os alunos ao longo dos momentos de formação que podem variar entre 20 e 60 horas-aula. Oferecendo reforço à Educação Básica e à formação prática na área da alimentação, os educadores conduzem os alunos nos momentos de aprendizado com aulas no contraturno das escolas nas quais eles estudam no horário regular. Tal Programa, porém, em muitos momentos apresenta uma formação muito tecnicista suprimindo por vezes formações que extrapolem a área técnica que poderiam auxiliar em uma formação integral dos sujeitos com uma perspectiva humanista.

Esta política municipal, estando ligada à área de educação, poderia percorrer vários itinerários formativos e estimular os alunos a entrarem no processo de empoderamento individual. Lançando mão das dinâmicas que ocorrem dentro de sala, os educadores possuem ferramentas diversas para facilitar os processos de aprendizagem dos discentes e estimulá-los a desenvolverem conceitos fundantes de sujeitos dotados de direitos e deveres dentro da sociedade a qual se inserem.

Objetivando analisar o Programa Pão Escola enquanto política de educação profissional (EP) como forma de um dispositivo que desperte o processo de empoderamento individual nos sujeitos, o presente estudo objetivou especificamente, levantar dados acerca dos processos formativos dos alunos; buscar informações a respeito dos níveis dos indicadores estabelecidos para esta pesquisa como potencialmente 'empoderadores', 
além de ouvir os alunos sobre a percepção de algumas áreas de suas vidas atualmente.

Tal estudo encontra-se dividido em cinco momentos, sendo a apresentação dos aspectos introdutórios, um breve levantamento teórico, a apresentação dos procedimentos metodológicos, a exposição dos dados e suas análises e, por fim, as considerações finais acerca da pesquisa.

\section{REFERENCIAL TEÓRICO}

\subsection{A Educação Profissional no Brasil}

A partir do momento em que o homem inicia os processos de transformação da natureza, iniciam-se dois grandes processos: o trabalho e a educação. O trabalho, entendido por Karl Marx como a transformação da realidade social (BAPTISTA, 2010; SILVA, MATA, KLEIN, 2010), aproxima-se e complementa-se com a educação, pois segundo Bertoldo (2010) e Tomé (2012), reconhecidamente são as melhores formas de transmissão de bagagem histórica e cultural dentro de uma comunidade. Tais atividades são consideradas essencialmente humanas (SAVIANI, 2007), tendo sido construídas pelo próprio homem partindo-se do trabalho como uma atividade hominizadora. O trabalho e a educação são os promotores e construtores da humanidade, são processos complementares e indissociáveis que formam e produzem os sujeitos (SAVIANI, 2007; TOMÉ, 2012).

A evolução da sociedade primitiva, a divisão social do trabalho e, consequentemente da sociedade em classes, força a educação a dividir-se em modalidades distintas as quais arrastam-se desde os primórdios da humanidade até os dias atuais. A formação dos sujeitos passa a apresentarse em duas vertentes dissociadas: a educação para os trabalhadores que serão responsáveis pela produção e manutenção da riqueza das classes superiores, com uma formação aligeirada que comprometerá toda a qualidade do ensino e a garantia dos direitos sociais (MACHADO, VELTEN, 2013), e a educação da classe dominante, que possuirá uma formação propedêutica que garantirá a eles a reafirmação dos seus poderes e status sociais adquiridos ao longo dos anos (MOURA, 2007; DIAS, MACHADO, FIGUEIREDO, 2016).

Para agravar cada vez mais esse dualismo, Tomé (2012) afirma que o modelo de gestão educacional é pautado pelo modelo estatal e, na maioria das vezes, pelo sistema de acumulação. Atualmente tal sistema requer a formação de intelectuais e trabalhadores em sujeitos distintos; é necessária a manutenção dos paradigmas postos há vários séculos: os dominadores e os dominados (DIAS, MACHADO, FIGUEIREDO, 2016). Dentro deste cenário, o sistema educacional brasileiro traz à tona e reforça cada dia mais essa cisão estrutural que aprofunda a divisão societária. 
Criado em 1809 por determinação de Dom João VI, o Colégio das Fábricas lançava a EP no Brasil, a qual apresentou-se inicialmente como uma vertente educacional para meninos pobres e desvalidos; com um viés assistencialista, esta forma de educação buscava atender às demandas por força de trabalho para o mercado agrícola e industrial do país. Com o avançar dos anos estes princípios apenas reforçam-se por meio de leis que regulamentavam os processos de ensino. Para tentar democratizar a escola para todos, o 'Manifesto dos Pioneiros da Educação Nova' ${ }^{2}$ propôs a organização da escola em duas áreas: as atividades humanas e ciências e os cursos de caráter técnico (DIAS, MACHADO, FIGUEIREDO, 2016).

Avançando da Era Vargas ao governo de Fernando Henrique Cardoso (1994-2002), várias foram as leis promulgadas que normatizaram, mesmo que indiretamente, a EP no país. Em meados de 1990 surge no Brasil o Plano Nacional de Qualificação Profissional (PLANFOR) que, qualificando a população jovem e adulta de baixa escolaridade, tornou-se uma mera oportunidade de certificação sem a garantia de quaisquer avanços nas vidas dos egressos (BARBOSA; DELUIZ, 2008).

Assumindo a presidência da República, os governos de esquerda Luís Inácio Lula da Silva (2003-2010) e Dilma Rousseff (2011-2016) - deram continuidade à criação de vários programas voltados para a EP, como PROEJA, ProJovem e PRONATEC, por exemplo, que objetivavam a expansão e democratização de tal formato educacional, porém segundo Figueiredo e Mueller (2015, p. 13), tais políticas continuam apenas respondendo às demandas projetadas pelo mercado sem necessariamente "ampliar as oportunidades educacionais dos trabalhadores".

\subsubsection{A Educação Profissional perante a dualidade educacional}

Os sistemas educativos são vistos atualmente com variadas formas de apresentação que vêm de encontro ao ideal dualista, como por exemplo: um sistema promotor do desenvolvimento da sociedade - com consequente melhora dos padrões de vida -, além de ser visto como um sistema que causaria atrasos e pobreza ao mesmo tempo em determinada localidade. Deve-se isso à reestruturação do sistema de acumulação do capital em meados da década de 70, quando passa-se a exigir dos trabalhadores, por exemplo, a necessidade da qualificação profissional para atender às novas demandas impostas por tal modelo de acumulação flexível (ALBERTO, 2005).

A educação a qual deveria promover a elevação da escolaridade, da cidadania e dos direitos dos sujeitos assume uma postura - frente ao cenário dualista - de ser uma mera ferramenta de dar novas formações aos trabalhadores para adequarem-se às atuais imposições e anseios do capital

\footnotetext{
${ }^{2}$ Redigido em 1932 por Fernando de Azevedo e outros 26 intelectuais, esse Manifesto se dizia assumir a perspectiva de uma escola democrática que pudesse proporcionar oportunidades para todos, tanto no que dizia respeito a uma cultura geral, como na possibilidade de especializações (MOURA, 2007).
} 
(CARMO, 2015). A educação profissional dentro deste contexto vale-se da necessidade que emana das organizações de possuírem trabalhadores adaptados e qualificados com novos conhecimentos, habilidades, maiores recursos de autoaprendizagem, polivalentes, entre outras necessidades, para remodelar-se e oferecer uma formação específica que atenda à escassez mercadológica demandada pelas mais diversas áreas (ROCHA-VIDIGAL, VIDIGAL, 2012).

As formas de qualificar e requalificar os trabalhadores passam a ser vistas como políticas que refletiriam diretamente, e positivamente, nas capacidades produtivas dos sujeitos - a partir de todo o exposto anteriormente - e, por consequência nas capacidades produtivas das organizações (STEFFEN, FISCHER, 2008). Com tal propósito volta-se a ratificar a força e maestria da dualidade educacional ao posicionar o trabalhador como uma ferramenta útil às organizações para elevação dos lucros e benefícios para uns poucos - classes dominantes.

De acordo com Dias, Machado e Figueiredo (2016, p. 15), a educação dual poderia privar os sujeitos de uma formação que impeça "a formação de cidadãos e sujeitos capazes de transformar essa realidade", as pessoas dentro de uma sociedade seriam alvos fáceis das disputas de poder, assim como seriam também alienadas nas mais variadas formas e dimensões (MORAES, SILVA, ROSSLER, 2010; SCHLESENER, 2015). Tal alienação apresentaria reflexos relevantes aos sujeitos: os homens afastar-se-iam de sua essência humana, de sua natureza, de seu ser genérico e de si próprio (MORAES, SILVA, ROSSLER, 2010), o que reafirmaria com cada vez mais exatidão as relações de segregação social.

\subsection{Empoderamento e Educação Profissional}

Amplamente discutido por vários autores (ROMANO, 2002; HOROCHOVSKI, MEIRELLES, 2007; PERKINS, 2010; BAQUERO, 2012; SOUZA, MOREIRA, BOURGUIGNON, 2014) o termo empoderamento encontra ainda uma grande polissemia atualmente. Surgido em meio às lutas pelos direitos civis na segunda metade do século $X X$, tal dispositivo influenciou-se de várias formas ao longo dos anos por meio de muitas correntes ideológicas, a saber: movimento negro, movimento feminista, movimentos de autoajuda, psicologia comunitária e movimentos que buscam a afirmação dos direitos de cidadania dentro da vida social (CARVALHO, 2004).

Condizente ao pensamento de Carvalho (2004), Silva e Wendhausen (2012) afirmam que o empoderamento representa o aumento do poder e da autonomia de pessoas, organizações ou comunidades, e por meio dele, estes sujeitos tomariam o controle de suas próprias situações, de suas próprias vidas. Para estes autores as pessoas que se empoderam deveriam ser sujeitos ativos dentro do processo. Romano (2002), Horochovski e Meirelles 
(2007) e Baquero (2012) vem também ao encontro a este pensamento da promoção da autonomia e da busca pela condução das próprias vidas.

É de fundamental importância destacar que o Programa das Nações Unidas para o Desenvolvimento (PNUD) da mesma forma, apresenta o conceito de empoderamento como uma concepção de participação, ele o vê como "a possibilidade de que todas as pessoas, mesmo pobres e marginalizadas, sejam ouvidas e possam participar de forma significativa dos debates que afetam as suas vidas" (UNDP, 2010, p. 115). Entende-se o empowerment como algo ligado ainda à democracia e direitos humanos (BORGES, MASCHIETTO, 2014).

Parte fundamental para a estimulação do empoderamento dentro de uma sociedade, a educação deve ser observada como fator primordial para trabalhar nos sujeitos seus potenciais humanos em sua totalidade. A educação direciona, segundo McCowan (2015), os processos de socialização e autonomia nas pessoas, ela é mola propulsora para as transformações dentro da sociedade na qual os sujeitos se inserem. A educação, como apresentado por Rodrigues (2009), Lombardi (2010), Ciavatta (2014) e Machado (2015), deveria trabalhar em uma linha emancipatória "no sentido de superar, na educação, a divisão social do trabalho entre trabalho manual/trabalho intelectual, e formar trabalhadores que possam ser, também, dirigentes" (CIAVATTA, 2014, p. 189).

Associando os pressupostos apresentados por Marx (1983), Rodrigues (2009), Lombardi (2010), Ciavatta (2014) e Machado (2015) às propostas de Baquero (2012), Silva e Wendhausen (2012) e McCowan (2015) é perceptível que a educação é uma das melhores formas de despertar e incentivar a autonomia dos sujeitos.

\subsection{Desenvolvimento Local e Empoderamento}

Associada à ideia do desenvolvimento econômico, o desenvolvimento local, tem seu ideal discutido hoje tendo por referencial o crescimento. De acordo com Oliveira (2001), já há algum tempo a Organização das Nações Unidas (ONU), vem tentando recuperar a semântica da nomenclatura apontando as dimensões mais qualitativas do termo, chegando a citá-lo como o 'desenvolvimento humano'. No geral, em um apontamento que se aproxima do alvo, mas ainda não o é, e valendo-se do dito da ONU, o desenvolvimento local poderia ser, em um âmbito mais restritivo, a contemplação de um conjunto de requisitos que levam ao bem-estar e à qualidade de vida (OLIVEIRA, 2001).

Para que ocorra um processo de desenvolvimento de determinada localidade, Gallichio (2002) afirma que é necessário o entendimento da existência de determinadas variáveis; uma delas é o território, que é visto muito além de um espaço físico onde as coisas acontecem, ele é uma variável do processo que auxilia na construção social atuando como condicionador ou condicionado a partir da ação dos atores. $O$ ator, por sua 
vez, atua como "aquele agente que no campo político, econômico, social e cultural é portador de propostas que tendem a capitalizar melhor as potencialidades locais" (GALLICHIO, 2002, p. 82). Por fim os agentes do desenvolvimento local, que são chaves para o desenvolvimento, são facilitadores do processo - seres proativos, eles antecipam-se e anteveem cenários, o que lhes confere o poder de articular os diversos atores, recursos privados e estatais, a população beneficiária e os grupos sociais.

Surgido em meados dos anos 80, devido aos questionamentos das políticas nacionais e regionais, a ideia do desenvolvimento local, de acordo com Montenegro Gómez (2002), vem incorporando novos conceitos ao seu cerne tais como os aspectos políticos e sociais diante do fracasso da supervalorização dos aspectos econômicos. O desenvolvimento passa a ser visto atualmente com uma tripla condição, segundo o autor: a dimensão social, a econômica e a política.

\begin{tabular}{ccc}
\hline Social & Econômica & Política \\
\hline Educação, moradia, & Oportunidade de & \\
saúde, alimentação, & emprego, satisfação, \\
cultura e tradição & $\begin{array}{c}\text { distribuição das } \\
\text { riquezas }\end{array}$ & $\begin{array}{c}\text { Legitimidade política e } \\
\text { benefícios sociais }\end{array}$ \\
\hline
\end{tabular}

Quadro 1: Dimensões do desenvolvimento local

Fonte: autoral baseado em Montenegro Gómez (2002)

O Quadro 1 apresenta os aspectos que devem ser trabalhados dentro da perspectiva do desenvolvimento; o autor argumenta que esta tríade dimensional se encaixa perfeitamente nas principais divisas que devem nortear este tipo de desenvolvimento: a melhora da qualidade de vida, a diversificação da produção e a participação da população.

Nos moldes anteriores de desenvolvimento o Estado era visto como o promotor tanto da economia - para garantir o crescimento econômico quanto da oferta de serviços públicos, como educação e saúde. Observa-se, porém, que atualmente o espaço público vem perdendo o seu lugar ficando apenas com algumas parcelas da economia; o mercado (a partir dos princípios do capitalismo) entra como o regulador da economia e a mercantilização de alguns setores da sociedade como a educação e a saúde, por exemplo. Sob essa nova ótica de que quaisquer propostas opostas aos pensamentos do capitalismo serão banidas, o desenvolvimento local tem como meta atuar na cidadania reduzida de possibilidades dos cidadãos decorrente do processo desenvolvimentista (MONTENEGRO GÓMEZ, 2002).

Oliveira (2001), Gallichio (2002) e Martins, Vaz e Caldas (2010) apontam o desenvolvimento local como uma estratégia de construção desta cidadania reificada. Gallichio argumenta que a cidadania é proveniente de um processo cultural e social que implica um trabalho na sociedade para despertar o empoderamento das pessoas a fim de que reconheçam seus direitos, deveres e necessidades e busquem soluções para tal. $\mathrm{O}$ autor diz ainda que as pessoas deveriam ser partes ativas nos seus processos de Vol. 2 (2019) 
desenvolvimento, sendo necessária a "inserção laboral para a construção da cidadania; o trabalho como chave para a integração social, criação de cidadania e mobilidade social e espacial" (GALLICHIO, 2002, p. 88).

Ao apresentar o empoderamento como uma ferramenta essencial para a propulsão do desenvolvimento local, as autoras Kleba e Wendausen (2009) corroboram as ideias acima citadas ao afirmarem que o empoderamento seria um processo dinâmico que, por meio de aspectos cognitivos, afetivos e condutais, aumentaria a autonomia pessoal e grupal de determinados indivíduos que, submetidos anteriormente a situações de opressão e dominação, realizariam uma mudança em determinado contexto social. As autoras argumentam também que o empoderamento deveria fomentar a realização de alianças locais que garantiriam o espaço de discussão da opressão, bem como sua contextualização.

Ao estimular o desenvolvimento do 'poder' nos sujeitos locais, essas pessoas tornar-se-iam os atores apresentados por Gallichio (2002) que entenderiam os diversos problemas e proporiam as mais variadas soluções para tais demandas que muitas vezes não seriam notadas por pessoas exteriores a essas localidades.

A partir das discussões apresentadas nas obras de Horochovski e Meirelles (2007), Kleba e Wendausen (2009) e Baquero (2012), é clara a argumentação do empowerment como uma mola propulsora para 0 desenvolvimento. Os referidos autores "compreendem o empoderamento como um processo que inclui potenciais e competências individuais, sistemas de ajuda e práticas proativas e questões relacionadas a mudanças sociais e políticas" (KLEBA, WENDAUSEN, 2009, p. 738), sendo que por meio das ações empoderadoras os atores entrariam em um "processo articulado que integre a construção de uma consciência crítica com a ação, ou o desenvolvimento de capacidade real de intervenção e transformação da realidade" (BAQUERO, 2012, p. 183).

Para finalizar, Kleba e Wendausen (2009), alegam que ao lidar com as localidades, são fundamentais as experiências de distribuição de papéis a partir do conhecimento das capacidades desenvolvidas nos sujeitos nas mais diversas funções dentro do território; é dentro dele que podem ser encontradas instituições importantes para o cotidiano da comunidade. A partir das potencialidades, energias, do capital social e empoderamento dos atores seriam levadas a conclusão as mais diversas transformações sociais necessárias nas comunidades locais.

\subsection{Programa Pão Escola}

No momento atual são ofertados diversos cursos de educação profissional no mercado de ensino. Dentre os diversos campos existentes destacam-se as formações na área da cozinha, em várias linhas de atuação. Alguns destes cursos são ofertados na modalidade de qualificação e/ou 
capacitação na área de alimentação, os quais projetarão mais facilmente as pessoas para o mundo do trabalho.

Envolvido nesta concepção está o Programa Pão Escola, política de governo da Prefeitura Municipal de Belo Horizonte $(\mathrm{PBH})$ que "visa à qualificação na área de alimentos para estudantes da Rede Municipal de Educação" (PREFEITURA MUNICIPAL DE BELO HORIZONTE, 2011). Este Programa oferece cursos de qualificação na área da Gastronomia para jovens e adultos que estejam regularmente matriculados na Rede Municipal de Educação (RME). Dentro da rede encontram-se jovens na faixa etária entre 16-19 anos, através do Programa Floração, e adultos das mais diversas idades provenientes da educação de jovens e adultos (EJA).

Normatizado pela Portaria Conjunta SMED/SMASAN/SMATE no 001/2011, o Programa associa três secretarias municipais com o objetivo central de formar estes jovens para a sua inserção no mundo de trabalho. $O$ Programa oferta cursos como: "Auxiliar de Panificação, Auxiliar de Confeitaria, Confeitaria Caseira, Auxiliar de Cozinha, Salgados e Pizzas e Processamento Artesanal de Frutas" (PREFEITURA MUNICIPAL DE BELO HORIZONTE, 2015). Esses cursos qualificam os alunos e impulsionam sua entrada no mercado, uma vez que muitos dos concluintes são indicados para vagas de emprego em empresas parceiras.

Dentro do processo formativo, os alunos têm aulas práticas e teóricas sobre a área específica do curso, além de aulas de conteúdos curriculares da educação básica como, por exemplo, Matemática, Língua Portuguesa, História e outras disciplinas, que pode ser visto como atribuição da Secretaria Municipal de Educação (SMED) na portaria que regulamenta o Programa:

\footnotetext{
VII. elaborar, imprimir e distribuir a apostila complementar de matemática e de outras áreas do conhecimento que se fizerem necessárias, a fim de que os saberes e conteúdos das disciplinas curriculares da Educação Básica estejam integrados aos conteúdos específicos dos cursos de qualificação (PREFEITURA MUNICIPAL DE BELO HORIZONTE, 2011, p. 1).
}

Tal projeto surgiu em 2001 e segue até os dias de hoje ofertando os mesmos cursos para a qualificação dos jovens e adultos. Os alunos recebem vale-transporte, todo o material didático do curso, lanche todos os dias e a possibilidade de indicação de seus nomes para vagas de emprego na área do curso via Sistema Nacional de Empregos (SINE). Este projeto conta com a parceria de algumas empresas do setor privado e, em alguns casos, já insere o jovem no mercado logo após a conclusão dos cursos.

Ofertada como uma política pública, mantida por verba municipal, que objetiva inserir os jovens no mundo do trabalho o PPE oferece formação com duração variadas: de cursos rápidos (20 horas) a cursos mais longos (60 horas) como Auxiliar de Panificação Industrial, por exemplo. Os discentes podem realizar tais momentos de formação dentro de salas de aula com todos os maquinários pertinentes à futura área de atuação; o Mercado da 
Lagoinha oferece uma estrutura com cinco cozinhas pedagógicas, sendo a padaria-escola, o principal espaço do Programa analisado.

\section{METODOLOGIA}

Este trabalho analisou a formação ofertada aos alunos do Programa Pão Escola da Prefeitura de Belo Horizonte sob a perspectiva do empoderamento. Para tal, realizou-se um estudo de caso tendo como base lógica o método dedutivo (DINIZ, 2008). Observando a abordagem para esta pesquisa, os pesquisadores lançaram mão da qualitativa que ocupa o lugar de responder questões muito particulares (MINAYO, 2009a).

Foram coletados dados indiretos e diretos; incluso na documentação indireta estiveram presentes: o levantamento e análise de documentos oficiais dos órgãos pertinentes tais como MEC, PBH, SMASAN, SMATE e SMED; levantamento e análise de bibliografia sobre as temáticas relacionadas à pesquisa. A coleta direta baseou-se em pesquisa de campo realizada entre os meses de agosto e outubro de 2016 na qual, por meio de entrevistas estruturadas, os pesquisadores coletaram dados pertinentes ao estudo com um grupo de dezenove alunos egressos do Programa.

Os dados coletados foram examinados com base na análise de conteúdo temática proposta por Bardin (2016) a partir de oito categorias de análises com base no referencial teórico levantado para a pesquisa, sendo elas: a EP como promotora da autonomia intelectual, como estimuladora ao pensamento crítico e ao poder decisório, como promotora da inserção econômica e social, como incentivadora à participação nos espaços públicos e, por fim, como geradora de mudanças nas realidades dos discentes; estão ainda a motivação para a busca pelos cursos e o protagonismo na vida.

\subsection{Caracterização da amostra}

No presente estudo, assim como descrito na metodologia, foram realizadas entrevistas com egressos do PPE para mensurar se tal política age como uma ferramenta educacional que impulsionaria 0 processo empoderador dos sujeitos. Para tal, o pesquisador entrou em contato com mais de 160 egressos certificados nos mais variados cursos de vários anos por meio de mídias sociais e telefonemas - a fim de recrutá-los para participar da pesquisa. Deste total participaram efetivamente do estudo dezenove ex-alunos do Programa. Os entrevistados receberam ao longo do estudo códigos para preservar a identidade dos mesmos e garantir o sigilo requerido por pesquisas científicas; os códigos foram distribuídos aleatoriamente e são compostos de numeração de 01 a 19 precedidos pela vogal 'E' - egresso.

Tais egressos ouvidos qualificaram-se no Programa nos anos de 2003 (1), 2011 (2), 2012 (3), 2013 (7), 2014 (1) e 2016 (5). Após o levantamento 
dos cursos realizados por eles (Tabela 1), descobriu-se que além dos cursos apresentados oficialmente - "Auxiliar de Panificação, Auxiliar de Confeitaria, Confeitaria Caseira, Auxiliar de Cozinha, Salgados \& Pizzas e Processamento Artesanal de Frutas" (PREFEITURA MUNICIPAL DE BELO HORIZONTE, 2015) -, há em execução atualmente os cursos de 'Massas e temperos' e 'Panificação aperfeiçoamento'.

\begin{tabular}{l|c}
\hline \multicolumn{1}{c|}{ Curso } & Egressos \\
\hline Auxiliar de Panificação & 17 \\
Auxiliar de Confeitaria & 13 \\
Salgados e Pizzas & 10 \\
Confeitaria Caseira & 9 \\
Auxiliar de Cozinha & 7 \\
Processamento artesanal de frutas & 7 \\
Panificação aperfeiçoamento & 2 \\
Massas e temperos & 1 \\
\hline
\end{tabular}

Tabela 1: Número de egressos da amostra por curso

Fonte: autoral

\section{RESULTADOS E DISCUSSOES}

\subsection{Análise categorial}

\subsubsection{A motivação}

Neste primeiro momento apurou-se que a maior parte das respostas dos egressos foi no sentido de que eles participaram dos cursos pois gostam de estar na cozinha, essa era a motivação primordial, dos dezenove exalunos, sete apresentaram tal justificativa. Três deles afirmaram buscar os cursos por curiosidade e/ou porque estavam desocupados. Dois buscaram os cursos por necessidade e outros três justificaram a busca pois, enxergavam na proposta do Programa uma oportunidade de inserção no mercado. Outros dois argumentaram ainda que viam no curso a opção para sair da escola ou ainda buscava uma forma de se alimentar.

\subsubsection{Autonomia intelectual}

Os alunos, quando questionados a respeito do PPE como uma política que estimula a formação humanista, apresentaram respostas divergentes. Do total da amostra, sete egressos argumentaram que a formação dada pelos professores trabalhava alguns aspectos humanísticos da sociedade, como cidadania, aspectos sociais e direitos humanos.

O restante dos egressos (doze) argumentou que não havia nada relacionado a este tipo de formação, e que, quando existia ocorriam em 
algumas vezes, em pequenos momentos. Tais dados apontam em sentido antagônico ao que é proposto pelos teóricos, uma vez que eles enfatizam que "antes do operário, existe o homem que, embora subjugado pela máquina, não deve ser impedido de percorrer os mais amplos horizontes do espírito" (CARMO, 2009, p. 56).

Ao avaliar-se a formação técnica ofertada pelos cursos, grande parte dos ex-alunos (quatorze) afirmaram que a formação ofertada era quase em sua totalidade prática - dentro da cozinha. As aulas eram dadas preparandoos para a prática no mercado.

Tais afirmações obtidas reforçam o ideal apontado pelos autores Dias, Machado e Figueiredo (2016) sobre a privação da educação integral ao reforçar uma educação focada essencialmente nas atividades técnicas. Alves e Vieira (1995) corroboram este ideal ao garantirem ser necessária para a EP 'tradicional' a formação técnica e polivalente dos egressos na qual é requerida, dentre outros fatores, a multifuncionalidade; contrário ao ideal emancipador e empoderador de uma EP que forme os sujeitos na integralidade humana.

\subsubsection{Inserção econômica e social}

Provocados em relação à habilitação que os cursos frequentados ofereciam para o trabalho na área de alimentação, quatorze egressos afirmaram que se sentem seguros e prontos para inserirem-se no mundo do trabalho nesta área. Outros dois ex-alunos afirmaram que não se sentem seguros ainda.

Ao avaliar a inserção e manutenção no mundo do trabalho, oito egressos afirmaram terem conseguido emprego a partir dos cursos do PPE, sendo as padarias e confeitarias as áreas mais citadas; um dos entrevistados argumentou que trabalhou antes da participação nos cursos. Do total dos egressos inseridos no mundo do trabalho devido à EP apenas 50\% deles conseguiram se manter na área.

Quando questionados sobre os benefícios advindos da certificação do Programa, sete alunos expressaram que obtiveram vantagens a partir dos cursos. Dentre estes benefícios estão a promoção interna, obtenção de novo emprego, serviços extra - freelance - e proposta de emprego.

Analisando, pois, a inserção econômica e social dos egressos do Programa nota-se que, na análise dos ex-alunos, os cursos ofertam uma boa formação (82\% veem-se como capacitados para o exercício das funções), insere uma baixa parcela e mantém um número menor no mundo do trabalho, além de garantir alguns benefícios para os mesmos em suas relações profissionais. 


\subsubsection{Atuação em espaços comunitários}

A primeira verificação deu-se no campo local de cada egresso, neste momento os pesquisadores questionaram a respeito da participação em redes, movimentos, organizações ou alguma outra associação em suas comunidades. Dos egressos, apenas seis responderam positivamente, apresentando áreas de atuação diversas dentro de suas comunidades tais como igrejas, coletivo urbano e reuniões no colégio.

Observando-se a participação nos espaços públicos é perceptível que apenas três dos entrevistados não frequentam qualquer ambiente comunitário. Os demais entrevistados levantaram uma série de locais onde eles se veem e participam com frequência. Dentre eles estão: praças, parques, cinemas e museus. Alguns dos egressos, porém, afirmaram que atualmente não participam de tais espaços uma vez que veem essas ações como responsabilidade ou tarefa do mundo escolar

Por fim quando provocados em relação à participação em movimentos sociais, apenas dois egressos afirmaram possuir algum tipo de vinculação com tais segmentos da sociedade. O E11 e o E17 afirmaram em seus depoimentos que mesmo antes de participar do PPE já eram militantes sociais.

Ao analisar todo o exposto é evidente que na área de participação em organizações e movimentos de contexto comunitário, os egressos participam de forma discreta em seus contextos comunitários, apropriam-se de locais públicos - tais como parques e museus - porém quase inexiste atividade no que tange os movimentos sociais, espaços de debates que poderiam afetar suas vidas, como reforça UNDP (2010).

\subsubsection{O protagonismo na vida}

Questionados a respeito da independência, dez ex-alunos afirmaram que se veem como sujeitos independentes e afirmaram que o PPE ajudou muito, por exemplo. Apenas um certificado especificamente disse já ser independente antes mesmo de ingressar no Programa.

A proatividade, segunda unidade de registro desta categoria, visou levantar, a partir da percepção dos sujeitos, se eles apresentam comportamento de tomada de decisão por antecipação, a realização de tarefas de forma a avaliar os possíveis cenários e outras variáveis. Neste questionamento treze egressos garantiram ser pessoas proativas. Dentro deste grupo, porém, alguns sujeitos demonstraram certa dificuldade na interpretação da variável, mesmo com as explicações do pesquisador alguns entrevistados não conseguiram assimilar o conceito apresentado. Do restante dos entrevistados um afirmou ser muito dependente dos outros e por isso não se vê como ser proativo; sendo que os demais optaram por não se manifestar. 
Nesta categoria de análise do empoderamento, a teoria apresentada pelos autores, vem parcialmente de encontro ao depoimento de alguns exalunos ao perceberem-se como independentes e proativos em suas vidas.

Os sujeitos veem-se como pessoas que se enquadram nestes conceitos, porém, de acordo com os pressupostos dos teóricos (ROMANO, 2002; HOROCHOVSKI, MEIRELLES, 2007; BAQUERO, 2012), os sujeitos não necessariamente o são; em momento algum eles perpassam pelos conceitos agregados à independência ditados pelos estudiosos, como autonomia, cidadania, direitos, deveres, projeção de cenários e situações.

É notório ressaltar, porém, que quase metade dos egressos afirmaram que o Programa não estimulou a independência em suas vidas.

\subsubsection{O pensamento crítico}

Sobre o estímulo proveniente das aulas para o desenvolvimento de tal forma de pensamento nos alunos, treze egressos afirmaram que a dinâmica de trabalho em sala auxiliou positivamente a cada um deles. Destes exalunos apenas dois responderam que o pensamento crítico foi desenvolvido em várias áreas da vida. Outros quatro afirmaram que o posicionamento está ligado diretamente à cozinha e às práticas culinárias. O restante dos egressos declarou que já era crítico (um certificado) ou não se desenvolveram durante as aulas (cinco ex-alunos).

Os reflexos de tal pensamento na vida dos egressos também foram questionados e, de uma forma expressiva, treze deles confirmaram que tal posicionamento os auxilia ou poderia auxiliar em suas vidas atualmente se tivesse sido melhor estimulado durante as aulas. Dentre as áreas de reforço, destacaram-se a não acomodação, a busca pelos desejos ou sonhos, o surgimento da prudência para solucionar problemas, a ampliação da visão para coisas novas, as novas exigências, curiosidades e o despertar de processos inovadores.

Nota-se que ao observar a área do pensamento crítico, uma boa fração dos egressos afirmaram de forma positiva que o curso os assistiu neste tópico, tanto no estímulo quanto no auxílio na vida atual. Faz-se necessário, porém, destacar que alguns egressos notaram o posicionamento crítico diretamente na cozinha - área de atuação dos cursos -, e não em suas vidas no sentido integral (FREIRE, 1987; BAQUERO, 2002; GOHN, 2002; MCCOWAN, 2015).

\subsubsection{O poder decisório}

O questionamento inicial sobre o incentivo ao desenvolvimento do poder decisório dos alunos foi apresentado pela maioria dos egressos (dez deles) com uma resposta negativa. Os ex-alunos afirmaram que não haviam estímulos ou desafios; observando-se as respostas que mencionavam os educadores ' $X$ ' e ' $Z$ ' houve ainda recorrência na afirmativa de que os 
discentes não tinham que tomar nenhuma decisão. As repostas apresentaram afirmação positiva para nove dos entrevistados; tais egressos declararam que outro educador, ' $\mathrm{Y}$ ', tentava incitar este recurso ao trazer situações para a resolução dentro da cozinha.

Ao responderem sobre o auxílio em suas vidas apenas nove ex-alunos se sentiram aptos para responder. Deste total cinco afirmaram que ajuda bastante pois eles agora são mais decididos, não agem por impulso e os demais reagiram com afirmações mais genéricas. Outros quatro afirmaram que se fossem encorajados mais fortemente veriam reflexos positivos.

É perceptível que o estímulo a este tipo de processo pode ser influenciado pelas características dos educadores - ações e práticas pedagógicas - dentro de sala, como trazido pelos entrevistados. O poder de decisão é visto de uma forma benéfica pelos egressos e é entendido como uma prática que pode refletir positivamente em suas vidas como aponta Horochovski e Meirelles (2007); através de uma prática decisória firme e bem estruturada os sujeitos poderão lidar melhor - com voz ativa - inclusive nas ações em agendas decisórias de políticas públicas (ROMANO, 2002; BAQUERO, 2012).

\subsubsection{A mudança na realidade}

Solicitados para regressarem ao estágio anterior ao Programa e avaliarem-se agora para levantar quais foram as transformações principais em todos os campos de suas vidas, apenas um dos entrevistados afirmou não possuir nenhuma mudança (E05). Nove ex-alunos garantiram que as mudanças em suas vidas se fixaram no campo culinário.

É perceptível através das afirmações dos entrevistados, as transformações de suas vidas. Porém, de forma oposta aos argumentos dos autores principais desta categoria, tais modificações enquadram-se na área de atuação do curso. Os entrevistados trazem as principais modificações e enxergam nelas grandes áreas de melhora, entretanto tais regiões podem ser apenas uma pequena parcela de uma integralidade superior que necessite de mais atenção e real modificação.

\subsection{Diagrama da aranha do empoderamento}

Observando os estudos de Oakley e Clayton (2003) que afirmam ser válido trazer para um diagrama, valores quantificados por meio de variáveis pré-estabelecidas nas análises qualitativas, os pesquisadores solicitaram ainda aos egressos que atribuíssem dados mensuráveis para cinco categorias analisadas.

Para a construção da aranha foram pontuadas apenas cinco das oito categorias finais explicitadas anteriormente, a saber: protagonismo na vida, poder decisório, pensamento crítico, atuação nos espaços comunitários e mudança de vida. A opção da supressão das outras três categorias justifica- 
se pela seguinte razão: a motivação não influi no empoderamento, ela foi trazida apenas para facilitar o entendimento da opção pela qualificação; a inserção econômica e social apresentou na seção anterior dados numéricos contundentes que explicitam de forma clara a baixa inserção dos egressos; por fim a autonomia intelectual não foi trazida pois ela é fortemente influenciada pelo pensamento crítico e pode refletir diretamente no protagonismo na vida - categorias contempladas no diagrama.

Conforme a afirmação de Minayo (2009b, p. 84) de que os indicadores são "parâmetros quantificados ou qualitativos que servem para detalhar se os objetivos de uma proposta estão sendo bem conduzidos" os alunos conferiram notas de 0 a 5 para as categorias constitutivas do diagrama.

Neste momento os pesquisadores apresentaram aos alunos a necessidade de, pautado em toda a conversa desenvolvida, analisar estes indicadores antes e depois dos cursos do PPE. Relembrando os conceitos principais e imprescindíveis para a atribuição das notas, os alunos geraram ao final deste exercício dados que foram plotados no 'diagrama da aranha do empoderamento' (Gráfico 1) com o objetivo de apresentar de forma visual os pensamentos dos egressos a respeito das alterações em suas vidas. Tal diagrama foi elaborado a partir da média dos dados dos egressos em cada um dos indicadores.

Observando-se os dados coletados no Gráfico 1, é possível fazer um comparativo entre os discursos apresentados pelos egressos nas seções anteriores com os valores dispostos no diagrama citado.

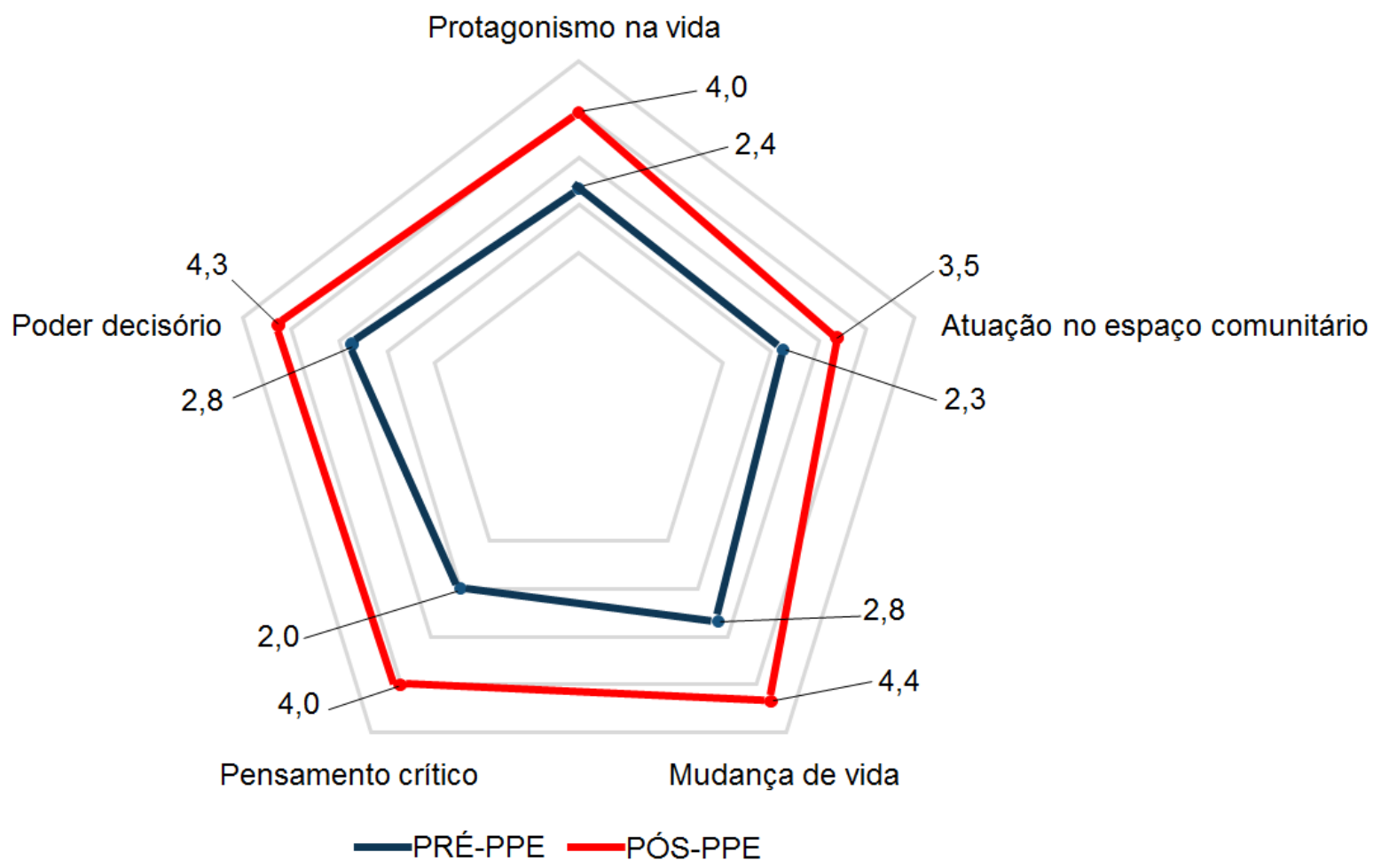

Gráfico 1: Diagrama da aranha do empoderamento dos egressos do PPE Fonte: autoral 
A categoria 'protagonismo na vida' apresentou um crescimento de $32 \%$ a partir do valor inicial estabelecido atingindo a média final de 4 pontos. $\mathrm{Na}$ seção 4.1.5, na qual estão as devolutivas dos egressos, os dados podem corroborar tal crescimento, uma vez que a parte majoritária dos entrevistados se veem como seres independentes e sujeitos proativos. É conveniente relembrar que os conceitos de 'independência' dos egressos não necessariamente dizem respeito à vida de uma forma geral.

No que diz respeito ao poder decisório há uma lacuna entre os discursos iniciais dos sujeitos (seção 4.1.7) e os dados apresentados no Gráfico 1. Próximo de $60 \%$ dos egressos afirmaram não haver o estímulo adequado a este recurso dentro do Programa - além de entenderem a importância de sua aplicação prática na vida - sendo que mesmo assim há um crescimento de $30 \%$ do valor final em referência ao inicial no diagrama acima apresentado.

Analisando-se os valores relativos ao 'pensamento crítico', o diagrama do empoderamento vem ao encontro dos discursos da seção 4.1.6. Neste momento os sujeitos elevaram em $40 \%$ a nota final atribuída ao indicador, o que reforça seus enunciados de que o Programa (para boa parte dos egressos) estimulou-os neste segmento de observação do pesquisador.

$\mathrm{Na}$ perspectiva da mudança de realidade as informações descritas ao longo da seção 4.1.8, deixam clara a percepção da mudança na vida dos egressos participantes da pesquisa. Mesmo exposto que as transformações ficaram, em sua maioria, apresentadas nas práticas culinárias - apenas um dos egressos afirmou não ter ocorrido nada em sua vida - tal fato pode ter justificado a elevação do percentual da nota final do indicador no Gráfico 1, colocando-a no maior patamar: 4,4 em 5,0.

Por fim na análise da participação nos espaços públicos os dados coletados na seção 4.1.4 podem ter correspondência com os valores descritos no diagrama da aranha. Com a menor taxa de crescimento do valor final (24\%) os dados relativos à atuação comunitária são os mais baixos segundo o Gráfico 1, o que vem ao encontro com a baixa presença e atuação dos egressos nesses locais.

\section{CONSIDERAÇÕES FINAIS}

O empoderamento, sendo um conceito polissêmico, é facilmente manipulado para apresentar-se na medida que convém ao emissor como por exemplo: uma proposta de um processo libertário, emancipador, no qual seriam trabalhadas as potencialidades humanas em toda sua totalidade em resposta a uma população pobre e vulnerável que muitas vezes é esquecida pelas classes dominantes, ou dentro da agenda de organizações que na realidade apresentariam propostas desempoderadoras para estes públicos 
(SHOR, FREIRE, 1986; PERKINS, ZIMMERMANN, 1995; ROMANO, ANTUNES, 2010; SOUZA, MOREIRA, BOURGUIGNON, 2014).

O Programa em análise encaixa-se em um órgão do executivo municipal que lida diretamente com as políticas sociais dentro da sociedade belo-horizontina e oferta à população jovem uma oportunidade de qualificação que poderia auxiliar na inserção no mundo do trabalho e promover uma melhora da qualidade de vida deste público.

Com motivações diversas para a busca de tal política, o PPE tem trabalhado nos últimos anos com uma estrutura pedagógica que oferta muita formação tecnicista (prática dentro da cozinha) e não apresenta tal empenho na área da formação humana e intelectual dos discentes. A demasiada valorização do tecnicismo formativo remete aos discursos anteriores da necessidade da formação de sujeitos enquanto mão de obra; os paradigmas são cada vez mais reforçados e mantidos.

No que compete às variáveis envolvidas no empoderamento é válido ressaltar que $65 \%$ dos egressos veem-se como sujeitos empoderados, eles entendem que o curso os deixou mais críticos, reflexivos, dedicados, seguros e decididos. Porém, de acordo com a base teórica, o empowerment é baseado em todo um processo contínuo de aprendizagem e desenvolvimento das potencialidades humanas e, através dos dados coletados, nota-se que tais conceitos não estão presentes nos depoimentos dos egressos acerca do Programa. Mesmo com o diagrama da aranha (Gráfico 1) apontando para um caminho de melhora, o que se nota por meio da análise dos depoimentos com a base teórica é que o PPE não atua de forma efetiva neste recorte.

O empoderamento deve ser trabalhado continuamente e a educação é vista como um dispositivo que pode atuar como facilitador deste processo de evolução pessoal. $O$ baixo incentivo à apropriação e participação dos espaços públicos, a falta do incentivo ao poder de decisão e as mudanças mais expressivas em suas vidas sendo basicamente na área da culinária, podem comprometer todo o 'potencial empoderador' do Programa. A tríade necessária para o desenvolvimento trazida por Montenegro Gómez (2002) não é visualizada nos depoimentos dos egressos, o que comprometeria todos os efeitos benéficos que poderiam ser obtidos.

A divergência de discursos apresentados ao longo do estudo leva a entender que a influência da prática pedagógica do professor e do educador afetam o desenvolvimento dos discentes em sala de aula e fora dela. É notório o reflexo da influência dos professores e educadores nos discursos dos alunos. Ao ouvir egressos que trabalharam com variadas combinações de professores e educadores nos cursos, percebe-se de forma clara tais variações de posições e discurso.

Uma política pública que lida diretamente com a educação profissional e pode ter um papel fundamental no processo de empoderamento dos alunos da RME do município de Belo Horizonte encontra-se, no presente momento, na contramão no que se refere ao seu potencial libertário. A necessidade de uma proposta de formação mais humanista que trabalhe nos discentes todas 
as áreas do desenvolvimento humano, levando-os a se tornarem seres reflexivos, autônomos, com grande potencial crítico e decisório refletirá diretamente em um egresso dotado de domínio técnico - habilitado para o mundo do trabalho -, e, acima de tudo, um cidadão reflexivo em constante processo de empoderamento.

O presente trabalho alcançou seu objetivo inicial de analisar 0 Programa como uma ferramenta que poderia - e não o faz na totalidade despertar o processo de empoderamento individual nos discentes. Teve por fim limitações no que se refere ao tempo da pesquisa e a disponibilidade e adesão dos egressos à proposta do estudo. Sugere-se ainda que posteriores trabalhos venham complementar os dados aqui coletados, sejam aprofundando as análises ou propondo mudanças à estrutura do Programa para oferecer uma ferramenta eficiente no que tange ao empoderamento individual.

\section{REFERÊNCIAS}

ALBERTO, M. A. A noção de empregabilidade nas políticas de qualificação e educação profissional no Brasil nos anos de 1990. Trabalho, Educação e Saúde, v. 3, n. 2, p. 295-330, 2005.

ALVES, E. L. G.; VIEIRA, C. A. S. Qualificação profissional: uma proposta de política pública. Planejamento e Políticas Públicas, n. 12, 1995.

BAPTISTA, M. G. A. Práxis e Educação em Vigtosky. Revista eletrônica Arma da Crítica, n. 2, p. 120-142, 2010.

BAQUERO, R. V. A. Empoderamento: instrumento de emancipação social? Uma discussão social. Revista Debates, v. 6, n. 1, p. 173-187, 2012.

BARBOSA, C. S.; DELUIZ, N. Qualificação Profissional de Jovens e Adultos trabalhadores: o Programa nacional de estímulo ao primeiro emprego em discussão. B. Téc. SENAC: a R. Edu. Profissional, v. 34, n. 1, p. 51-63, 2008.

BARDIN, L. Análise de conteúdo. São Paulo: Edições 70, 2016.

BERTOLDO, E. A concepção marxista de educação em Leontiev. Arma da Crítica, n. 2, p. 189-204, 2010.

BORGES, M.; MASCHIETTO, R. H. Cidadania e empoderamento local em contextos de consolidação da paz. Revista Crítica de Ciências Sociais, n.105, p. 65-84, 2014.

CARMO, J. C. Notas sobre a escola unitária e trabalho no pensamento de Antonio Gramsci. Cadernos Cemarx, n. 5, 2009. 
- Institutos federais de educação, ciência e tecnologia, no contexto das novas formas de trabalho e educação. Trabalho e Educação, v. 24, n. 3, p. 91-103, 2015.

CARVALHO, S. R. Os múltiplos sentidos da categoria "empowerment" no projeto de Promoção à Saúde. Cadernos de Saúde Pública, Rio de Janeiro, v. 20, n. 4, p. 1088-1095, 2004.

CASSIOLATO, M. M. C.; GARCIA, R. C. PRONATEC: múltiplos arranjos e ações para ampliar o acesso à educação profissional, IPEA, Brasília. Rio de Janeiro: IPEA, 2014.

CIAVATTA, M. O ensino integrado, a politecnia e a educação omnilateral. Por que lutamos? Trabalho \& Educação. v.23, n.1, p. 187-205, 2014.

DINIZ, C. R. Metodologia Científica. Campina Grande; Natal: UEPB/UFRN EDUEP, 2008.

FIGUEIREDO, A. C.; MUELLER, R. R. A política de educação profissional e tecnológica: uma análise do Programa Nacional de Acesso ao Ensino Técnico e Emprego (PRONATEC). 3o Encontro Internacional de Política Social e 10ํㅡㄴ Encontro Nacional de Política Social. Vitória: [s.n.], 2015.

DIAS, F. D.; MACHADO, L. R. S.; FIGUEIREDO, F. C. A Dualidade do Sistema educacional e a Educação Profissional à luz da divisão do trabalho em Marx. In: SImpósio Nacional Educação, Marxismo e Socialismo, 1, 2016, Belo Horizonte. Anais. Belo Horizonte, 2016.

FREIRE, P. Pedagogia do oprimido. Rio de Janeiro: Paz e Terra, 1987.

GALLICHIO, E. Empoderamento, teorias de desenvolvimento e desenvolvimento local na América Latina. In: Romano, Jorge O.; Antunes, Marta (Org.). Empoderamento e direitos no combate à pobreza. Rio de Janeiro: ActionAid Brasil, 2002.

GODOY, A. S. Pesquisa qualitativa tipos fundamentais. Revista de administração de empresas, São Paulo, v. 35, n. 3, p. 20-29, 1995.

GOHN, M. G. Educação popular na América Latina no novo milênio: impactos do novo paradigma. ETD - Educação Temática Digital, Campinas, v. 4, n. 1, p. 53-77, 2012.

HOROCHOVSKI, R. R.; MEIRELLES, G. Problematizando o conceito de empoderamento. In: Seminário Nacional Movimentos Sociais, Participação e Democracia, 2, 2007, Florianópolis. Anais: II Seminário Nacional Movimentos Sociais, Participação e Democracia, Florianópolis, UFSC, 2007.

IBGE. Séries históricas e estatísticas. Disponível em <http://seriesestatisticas.ibge.gov.br/series.aspx?vcodigo=PD322>. Acesso em 30 out. 2015

KLEBA, M. E.; WENDAUSEN, A. Empoderamento: processo de fortalecimento dos sujeitos nos espaços de participação social e 
democratização política. Saúde e Sociedade. São Paulo, v.18, n.4, p.733743, 2009.

KUENZER, A. Exclusão includente e inclusão excludente: a nova forma de dualidade estrutural que objetiva as novas relações entre educação e trabalho. In: Saviani, D., Sanfelice, J.L. \& Lombardi, J.C. (Org.). Capitalismo, trabalho e educação. 3. ed. Campinas: Autores Associados, p. 77-96, 2005.

LOMBARDI, J. C. Reflexões sobre educação e ensino na obra de Marx e Engels. Campinas, SP: Tese (livre docência) - Universidade Estadual de Campinas, Faculdade de Educação, [s.n.], 2010.

MACHADO, L. R. S.; VELTEN, M. J. Cooperação e colaboração federativas na educação profissional e tecnológica. Educação e Sociedade, Campinas, v. 34, n. 125, p. 1113-1133, 2013.

MACHADO, L. R. S. Processos Pedagógicos na Educação Profissional e Tecnológica. 2015. In: Biagini, Jussara; Vasconcelos, Fernanda. Educação profissional: formação, valorização e trabalho docente. Belo Horizonte. p. 14-39, 2015.

MANFREDI, S. M. Trabalho, qualificação e competência profissional - das dimensões conceituais e políticas. Educação e Sociedade, Campinas, v. 9, no 64, 1998.

MARTINS, R. A.; VAZ, J. C.; CALDAS, E. L. A gestão do desenvolvimento local no Brasil: (des)articulação de atores, instrumentos e território. RAP, Rio de Janeiro, n. 44, p. 559-590, 2010.

MARX, K. Contribuição à Crítica da Economia Política. São Paulo: Martins Pontes, 1983.

MCCOWAN, T. O direito humano à aprendizagem e a aprendizagem dos direitos humanos. Educar em Revista, Curitiba, n. 55, p. 25-46, 2015.

MINAYO, M. C. S. (org.); GOMES, S. F. D. R. Pesquisa Social: Teoria, método e criatividade, 28aㅡ ed. Petrópolis: Vozes, 2009a.

MINAYO, M. C. S. Construção de Indicadores Qualitativos para Avaliação de Mudanças. Revista brasileira de educação médica, Rio de Janeiro, n. 33, p. 83-91, 2009b.

MONTENEGRO GÓMEZ, J. Crítica ao conceito de desenvolvimento. Pegada Eletrônica, Presidente Prudente, n.1, p. 20-32, 2002.

MORAES, R. J. S.; SILVA, G. L. R.; ROSSLER, J. H. A alienação e o sofrimento da classe trabalhadora: contribuições da psicologia históricocultural. Revista eletrônica Arma da Crítica, v. 2, p. 72-97, 2010.

MOURA, D. H. Educação básica e educação profissional e tecnológica: dualidade histórica e perspectivas de integração. Holos, v. 2, p. 4-30, 2007. 
OAKLEY, P.; CLAYTON, A. Monitoramento e avaliação do empoderamento ("empowerment"). Tradução de Zuleika Arashiro e Ricardo Dias Sameshima. São Paulo, Instituto Pólis, 2003.

OLIVEIRA, F. Aproximações ao enigma: o que quer dizer desenvolvimento local? São Paulo, Pólis; Programa Gestão Pública e Cidadania/EAESP/FGV, 2001.

PERKINS, D. Empowerment. In: Couto, Richard (Ed.). Purposes of Political and Civic Leadership. Thousande Oaks, CA: Sage Publications, Inc., 2010, p. 207-219. Disponível em <https://my.vanderbilt.edu/perkins/les/2011/09/25>. Acesso em 13 mai. 2016.

PERKINS, D.; ZIMMERMAN, M. Empowerment Theory, Research and Application. Amerincan Journal of Community Psychology. v. 23, n. 5, p. 569-579, 1995.

PREFEITURA MUNICIPAL DE BELO HORIZONTE. Balanço 2012 prestação de contas, 2012.

PREFEITURA MUNICIPAL DE BELO HORIZONTE. Portaria conjunta SMED/SMASAN/SMATE no001/2011, 2011.

PREFEITURA MUNICIPAL DE BELO HORIZONTE. Programa Pão Escola. Disponível em <http://portalpbh.pbh.gov.br/pbh/ecp/noticia.do?evento=portlet>. Acesso em 11 mai. 2015.

ROCHA-VIDIGAL, C. B.; VIDIGAL, V. G. Investimento na qualificação profissional: uma abordagem econômica sobre sua importância. Acta Scientiarum. Human and Social Sciences, Maringá, v. 34, n. 1, p. 41-48, 2012.

RODRIGUES, J. Dicionário da Educação Profissional em Saúde, 2009.

ROMANO, J. O. Empoderamento: recuperando a questão do combate à pobreza. In: Empoderamento e direitos no combate à pobreza. Rio de Janeiro: Action Aid Brasil, 2002.

ROMANO, J. O.; ANTUNES, M. Introdução ao debate sobre empoderamento e direitos no combate à pobreza. In: Empoderamento e direitos no combate à pobreza. Rio de Janeiro: Action Aid Brasil, 2002.

SAVIANI, D. Trabalho e educação: fundamentos ontológicos e históricos. Revista Brasileira de Educação, v. 12, n. 34, p. 152-165, 2007.

SCHLESENER, A. H. Marx e a educação: observações acerca da Ideologia Alemã e Teses contra Feuerbach. Germinal: Marxismo e Educação em Debate, Salvador, v. 7, n. 2, p. 163-175, 2015.

SEBRAE. Políticas Públicas: conceitos e práticas / supervisão por Brenner Lopes e Jefferson Ney Amaral; coordenação de Ricardo Wahrendorff Caldas - Belo Horizonte: Sebrae/MG, 48p., 2008. 
SENAI.DN. Pró-docente: curso de iniciação à docência na educação profissional e tecnológica / SENAI.DN. Brasília: [s.n.], 2011.

SHOR, I.; FREIRE, P. Medo e Ousadia - o cotidiano do professor. Rio de Janeiro: Paz e Terra, 1986.

SILVA, F. C. T.; WENDHAUSEN, A. L. P. Empoderamento em um grupo de mulheres de um município no sul do Brasil. Revista Grifos. n. 32/33, 2012.

SOUZA, C. G.; MOREIRA, D.; BOURGUIGNON, J. A. Aproximações entre participação e empoderamento em uma perspectiva emancipatória. Revista NUPEM, Campo Mourão, v. 6, n. 11, 2014.

SOUZA, C. Políticas Públicas: uma revisão de literatura. Sociologias, Porto Alegre, ano 8, n. 16, p. 20-45, 2006.

STEFFEN, E. M.; FISCHER, M. C. B. Qualificação profissional do técnico industrial em plásticos. Cadernos de Educação, Pelotas, № 31, p. 227-248, 2008.

TOMÉ, A. C. A. Trabalho e/ou educação: história da educação profissional no Brasil. \#tear: Revista de Educação, Ciência e Tecnologia, Canoas, v. 1, ㄲo 2, 2012.

UNDP. United Nations Development Programme, 2010. Human Development Report 2010. The Real Wealth of Nations: Pathways to Human Development. New York, 2010. 